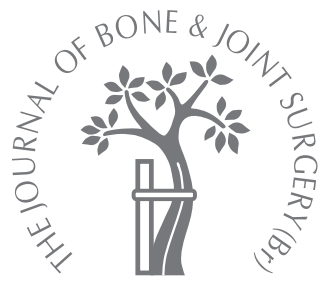

H. A. P. Archbold,

B. Mockford,

D. Molloy,

J. McConway,

L. Ogonda,

D. Beverland

From Musgrave Park Hospital, Belfast, Northern Ireland

H. A. P. Archbold, MRCS,

Belfast Arthroplasty Research Fellow

B. Mockford, MRCS, MPhil,

Specialist Registrar

D. Molloy, MRCS, Belfast Arthroplasty Research Fellow

- J. McConway, MRCS, Belfast

Arthroplasty Research Fellow

- L. Ogonda, FRCS, MPhil,

Specialist Registrar

D. Beverland, MD,

FRCS(Orth), Consultant

Orthopaedic Surgeon

Outcomes Unit

Musgrave Park Hospital,

Stockmans Lane, Belfast BT9

7JB, Northern Ireland.

Correspondence should be sent to $\mathrm{Mr} \mathrm{H}$. A. P. Archbold; e-mail: poolerarchbold@aol.com

(C)2006 British Editorial Society of Bone and Joint Surgery doi:10.1302/0301-620X.88B7. $17577 \$ 2.00$

$J$ Bone Joint Surg $[\mathrm{Br}]$ 2006;88-B:883-6.

Received 22 December 2005;

Accepted 1 February 2006

\title{
The transverse acetabular ligament: an aid to orientation of the acetabular component during primary total hip replacement
}

\author{
A PRELIMINARY STUDY OF 1000 CASES INVESTIGATING POST- \\ OPERATIVE STABILITY
}

\begin{abstract}
Ensuring the accuracy of the intra-operative orientation of the acetabular component during a total hip replacement can be difficult. In this paper we introduce a reproducible technique using the transverse acetabular ligament to determine the anteversion of the acetabular component. We have found that this ligament can be identified in virtually every hip undergoing primary surgery. We describe an intra-operative grading system for the appearance of the ligament. This technique has been used in 1000 consecutive cases. During a minimum follow-up of eight months the dislocation rate was $0.6 \%$. This confirms our hypothesis that the transverse acetabular ligament can be used to determine the position of the acetabular component. The method has been used in both conventional and minimally-invasive approaches.
\end{abstract}

In total hip replacement (THR) malposition of the acetabular component may lead to dislocation, impingement, wear and revision. ${ }^{1-9}$ This aspect of THR has not been lessened by the use of minimally-invasive techniques. ${ }^{10,11}$

Currently, many surgeons depend on precise positioning of the patient to orientate the acetabular component. However, this method cannot always be relied on. ${ }^{2,12,13}$ Although computer-assisted surgery ${ }^{14-17}$ has the potential to improve accuracy, the early results have been disappointing, ${ }^{16,18,19}$ with controversy continuing to exist regarding the optimal orientation. $^{20}$

The aim of this paper is to present the preliminary data on a technique which uses the transverse acetabular ligament to determine the anteversion of the acetabular component and to determine the effect of such positioning on the risk of dislocation. This technique was the sole method of determining the version of the component in 1000 consecutive primary THRs performed by the senior author (DB) using both conventional and minimallyinvasive approaches.

\section{Patients and Methods}

Between October 2002 and March 2005, 1000 consecutive patients underwent primary THR by the same surgeon (DB). This included 400 who had the operation through an incision of less than $10 \mathrm{~cm}$ in length. Of these latter patients, 104 were part of a separate prospective randomised controlled trial. ${ }^{21}$ The mean age of the 463 men and 537 women at the time of operation was 68.3 years (25 to 92). The indication for the primary THR was pain arising from idiopathic osteoarthritis in 936 patients (23 rapidly progressive), inflammatory arthritis in 28 , osteoarthritis secondary to osteonecrosis in nine, osteoarthritis secondary to congenital dysplasia of the hip in six, posttraumatic arthritis in 15, osteoarthritis secondary to a septic arthritis in two, and osteoarthritis secondary to slipped upper femoral epiphysis in four patients.

Operative technique. A posterolateral approach was used to insert a cementless acetabular component (Duraloc or Pinnacle; DePuy International Ltd., Warsaw, Indiana); the femoral component was either a custom-made cemented titanium component or a cemented C-stem (Depuy International Ltd, Leeds, United Kingdom) with a $28 \mathrm{~mm}$ head. Ceramic-on-ceramic bearings were used in patients under 60 years of age, while ceramic-on-polyethylene were used in patients aged 60 to 65 years and those over 65 years of age had metal-on-polyethylene bearings.

A neutral $28 \mathrm{~mm}$ acetabular liner was used in 973 cases. In 27 cases an acetabular liner with a $10^{\circ}$ lip was used. In 18 of these the lip was positioned superiorly to compensate for the fact that the component had been left open to maximise bone cover in cases with superior bone loss. In the remaining nine it had been inadvertently inserted in more than $5^{\circ}$ of retroversion with respect to the transverse acetabu- 


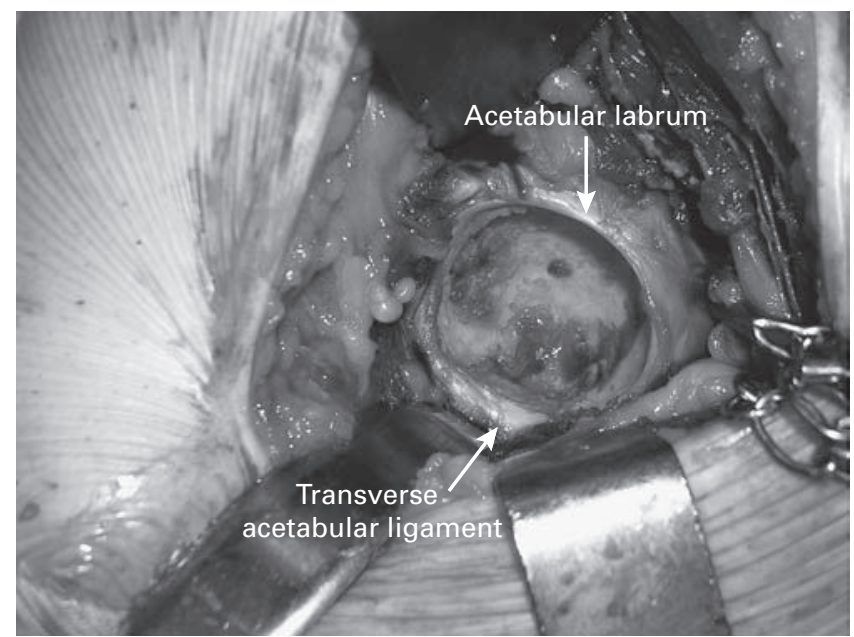

Fig. 1

A $360^{\circ}$ fixed-window exposure of the acetabulum, with exposure of the acetabular labrum and transverse acetabular ligament (grade 1).

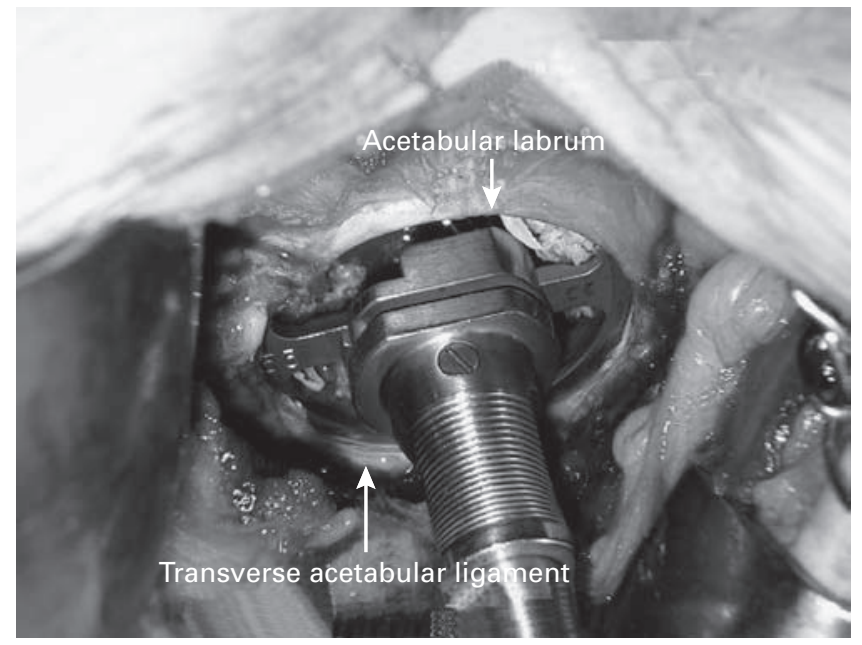

Fig. 2

The transverse acetabular ligament cradling the final acetabular reamer (representing the functional inlet plane of the acetabulum).
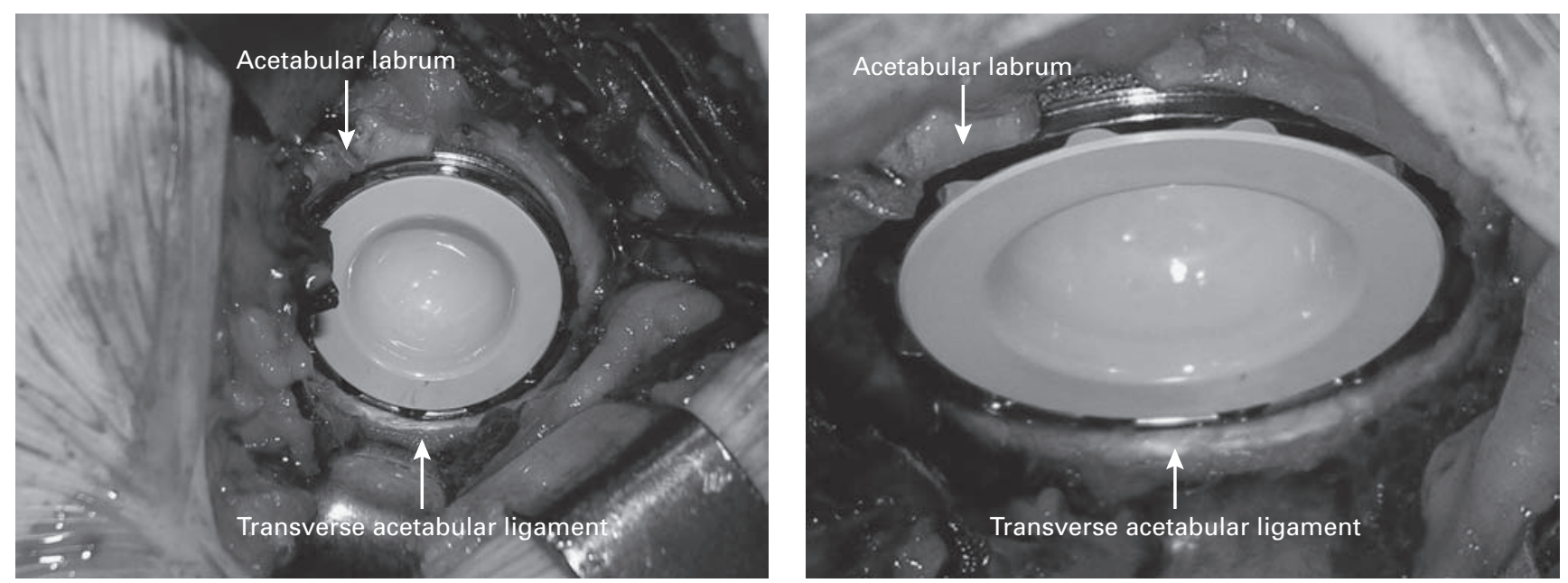

Fig. 3

Final orientation of the acetabular component using the transverse acetabular ligament/labrum technique.

Table I. Intra-operative classification of the transverse acetabular ligament (TAL) and the number of each grade identified in the 1000 total hip replacements (THRs)

\begin{tabular}{llc}
\hline Grade of TAL & The appearance of the TAL as seen during THR & $\begin{array}{l}\text { Number of each } \\
\text { grade identified (\%) }\end{array}$ \\
\hline 1 & Normal-quality TAL visible on exposure of the acetabulum & $490(49.0)$ \\
2 & TAL covered by soft tissue, which needed to be cleared to expose the ligament & $351(35.1)$ \\
3 & TAL covered by osteophytes, which have to be removed to expose the ligament & $156(15.6)$ \\
4 & No ligament identified, even after adequate clearance of soft tissue or osteophytes & $3(0.3)$ \\
\hline $\begin{array}{l}\text { Not infrequently the TAL was of mixed grade: for example, part of it was grade 1 and easily visible, but another part was cov- } \\
\text { ered in bone (grade 3). Rather than create additional grades, those that were of mixed were graded according to the most } \\
\text { predominant grade }\end{array}$
\end{tabular}




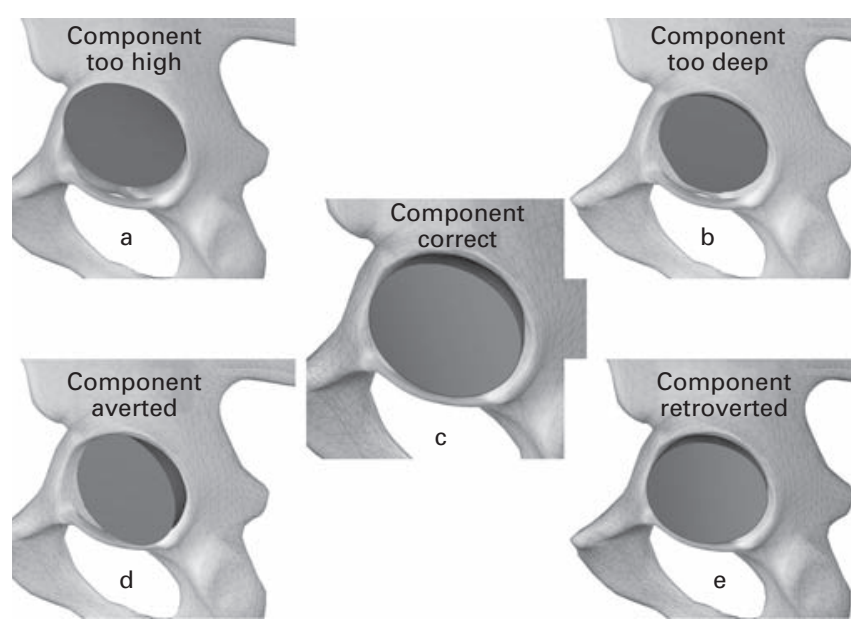

Fig. 4

The acetabular component sitting, a) high, b) deep, c) at the correct height, depth and version, d) at the correct height and depth, but anteverted, and e) at the correct height and depth, but retroverted.

Table II. Overview of the literature on the incidence of post-operative dislocation following total hip replacement (THR) by a posterior approach with a posterior repair

\begin{tabular}{|c|c|c|c|}
\hline Authors & $\begin{array}{l}\text { Number of } \\
\text { dislocations }\end{array}$ & $\begin{array}{l}\text { Number } \\
\text { of THRs }\end{array}$ & $\begin{array}{l}\text { Incidence of } \\
\text { dislocation (\%) }\end{array}$ \\
\hline Goldstein et $\mathrm{al}^{25}$ & 3 & 500 & 0.6 \\
\hline Weeden et $\mathrm{al}^{26}$ & 8 & 945 & 0.85 \\
\hline van Stralen et $\mathrm{al}^{27}$ & 12 & 884 & 1.36 \\
\hline White et $\left.a\right|^{28}$ & 3 & 437 & 0.7 \\
\hline Suh et $\mathrm{al}^{29}$ & 1 & 96 & 1 \\
\hline Dixon et $\mathrm{al}^{30}$ & 1 & 255 & 0.4 \\
\hline Archbold et al (present study) & 6 & 1000 & 0.6 \\
\hline
\end{tabular}

lar ligament, and the lip was then placed posteriorly. In all cases retractors were used to obtain full exposure of the acetabulum (Fig. 1). Inferiorly, this was achieved by using a teardrop retractor, which was placed such that the transverse acetabular ligament remained superficial to it. The appearance of this ligament was graded using a system developed in-house (Table I). Where the ligament was covered by osteophyte (grade 3), acetabular reamers were used to remove overlying bone to expose it. To achieve this, a small-diameter acetabular reamer was used. This should be done with care, because excessive reaming could potentially transform a grade 3 ligament into a grade 4 by destroying it.

Once defined, the transverse acetabular ligament is used as a guide to acetabular reaming (Fig. 2). When functioning normally the ligament acts as a tension band between the posteroinferior and anteroinferior aspects of the acetabulum, resisting anteroposterior widening during loading of the joint. ${ }^{22}$ To restore the anatomy, the ligament should embrace the final acetabular reamer (Fig. 2) and thereby, the acetabular component (Fig. 3). If there is a gap between the ligament and the reamer the acetabular component will sit too high (Fig. 4a). If the reamer is hemispherical, its inferior superficial edge should sit just inside the ligament. This acts as a control for depth as well as for height (Fig. $4 \mathrm{~b})$. When bone loss is present the cementless cup has to be placed deep to the ligament. In this situation an offset liner can be used to restore depth so that the face of the liner sits almost flush with the caudal edge of the ligament (Fig. 4c).

Thus the transverse acetabular ligament can be used to control acetabular depth, height and version. If the face of the reamer, and subsequently the acetabular component, is kept parallel to the ligament, we feel that this represents the natural version for that patient (Fig. 4c). Anteversion is demonstrated in Figure 4d and retroversion in Figure 4e. As the ligament cannot define the inclination of the component, this may be assessed with the residual labrum. By orientating the reamer, and hence the acetabular component, flush with the residual labrum, inclination can be controlled (Figs 2 to 4).

During closure, the capsule and short external rotators were individually reattached to the trochanter with number 5 Ethibond, using drill holes. Standard precautionary advice was given to the patient after the operation and no other specific action was taken to avoid dislocation. Where possible, the patients were mobilised on the day after surgery and were discharged when they were mobilising independently. The mean post-operative stay was 4.2 days ( 2 to 27).

\section{Results}

The transverse acetabular ligament was identified and exposed in $99.7 \%$ of cases (Table I). At a minimum followup of eight months (8 to 41) six of the 1000 hips $(0.6 \%$ ) had dislocated, all posteriorly.

\section{Discussion}

The transverse acetabular ligament forms a bridge across the inferior acetabular notch, continuing the outer edge of the acetabulum..$^{22}$ In this region it is effectively the continuation of the acetabular labrum, to which it is attached. The deep aspect of the ligament is attached to the bone beneath the lunate surface. To date, the function of this ligament is not fully understood ${ }^{23}$ and is often regarded merely as a surgical obstacle during arthroplasty of the hip. We used it as a landmark to control the positioning of the acetabular component. This technique is independent of the position of the patient. Although it cannot determine the inclination of the cup accurately, we feel that this can be defined by reference to the residual posterior labrum, which again is almost always present.

We have shown that the transverse acetabular ligament can be classified into four grades. Although it is a relatively short structure it can be exposed in most cases, even when 
using a minimally-invasive approach. In the three cases where it was absent, it is possible that the surgeon inadvertently destroyed a grade 3 ligament.

Using this technique, our rate of dislocation after surgery was $0.6 \%$. Many factors are known to contribute to this complication, but correct placement of the acetabular component is critical. ${ }^{2,7,24}$ These results compare favourably with those of other published series using a posterior approach $^{25-30}$ (Table II). A larger femoral head $(32 \mathrm{~mm})$ has been shown to be associated with a lower risk of dislocation, ${ }^{31}$ but we used a $28 \mathrm{~mm}$ head in all cases.

We conclude from this preliminary study that the transverse acetabular ligament can aid positioning of the acetabular component of a THR. It defines the version of the acetabular component without the need for external instrumentation, and is independent of the position of the patient. The low dislocation rate demonstrated in this study is consistent with the technique rather than necessarily attributable to it. It may not be applicable where a significant acetabular structural abnormality is present, as in severe dysplasia or following a pelvic fracture. These conditions were not encountered in our series of 1000 consecutive cases. Further work is being undertaken to determine how the position achieved by this technique relates to the suggested 'safe zones' on radiological assessment. ${ }^{1-4,6,7}$

\section{Supplementary Material}

远 A further opinion by Mr John Nolan is available with the electronic version of this article on our website at www.jbjs.org.uk

The author or one or more of the authors have received or will receive benefits for personal or professional use from a commercial party related directly or indirectly to the subject of this article. In addition, benefits have been or will be directed to a research fund, foundation, educational institution, or other nonprofit organisation with which one or more of the authors are associated.

\section{References}

1. Lewinnek GE, Lewis JL, Tarr R, Compere CL, Zimmerman JR. Dislocations after total hip-replacement arthroplasties. J Bone Joint Surg [Am] 1978;60-A:217-20.

2. McCollum DE, Gray WJ. Dislocation after total hip arthroplasty: causes and prevention. Clin Orthop 1990;261:159-70.

3. Ali Khan MA, Brakenbury PH, Reynolds IS. Dislocation following total hip replacement. J Bone Joint Surg [Br] 1981;63-B:214-18.

4. Dorr LD, Wan Z. Causes of and treatment protocol for instability of total hip replacement. Clin Orthop 1998;355:144-51.

5. Kummer FJ, Shah S, Slyer S, DiCesare PE. The effect of acetabular cup orientations on limiting hip rotation. J Arthroplasty 1999;14:509-13.

6. Jolles BM, Zangger P, Leyvraz PF. Factors predisposing to dislocation after primary hip arthroplasty: a multivariate analysis. J Arthroplasty 2002;17:282-8.
7. Biedermann R, Tonin A, Krismer M, et al. Reducing the risk of dislocation after total hip arthroplasty: the effect of orientation of the acetabular component. J Bone Joint Surg [Br] 2005:87-B:762-9.

8. Morrey BF. Instability after total hip arthroplasty. Orthop Clin North Am 1992;23: 237-48.

9. Yuan L, Shih C. Dislocation after total hip arthroplasty. Arch Orthop Trauma Surg 1999;119:263-6.

10. Noble PC, Sugano N, Johnston JD, et al. Computer simulation: how can it help the surgeon optimize implant position. Clin Orthop 2003;417:242-52.

11. Berry D. "Minimally Invasive" total hip arthroplasty. J Bone Joint Surg [Am] 2005; 87-A:699-700.

12. Hassan DM, Johnston GH, Dust WN, Watson G, Dolovich AT. Accuracy of intraoperative assessment of acetabular prosthesis placement. J Arthroplasty 1998;13: 80-4.

13. Asayama I, Akiyoshi Y, Naito M, Ezoe M. Intraoperative pelvic motion in total hip arthroplasty. J Arthroplasty 2004;19:992-7.

14. Amiot LP, Poulin F. Computed tomography-based navigation for hip, knee, and spine surgery. Clin Orthop 2004;421:77-86.

15. Nolte LP, Beutler T. Basic principles of CAOS. Injury 2004;35(Suppl 1):6-16.

16. Grutzner PA, Zheng G, Langlotz $\mathbf{U}$, et al. C-arm based navigation in total hip arthroplasty-background and clinical experience. Injury 2004;35(Suppl 1):90-5.

17. Kahler DM. Image Guidance: fluoroscopic navigation. Clin Orthop 2004;421:70-6.

18. Jaramaz B, DiGioia AM III, Blackwell M, Nikou C. Computer assisted measurement of cup placement in total hip replacement. Clin Orthop 1998;354:70-81.

19. Langlotz F. Potential pitfalls of computer aided orthopedic surgery. Injury 2004;35 (Suppl 1):17-23.

20. Paterno SA, Lachiewicz PF, Kelley SS. The influence of patient-related factors and the position of the acetabular component on the rate of dislocation after total hip replacement. J Bone Joint Surg [Am] 1997;79-A:1202-10.

21. Ogonda L, Wilson R, Archbold $\mathbf{P}$, et al. A minimal-incision technique in total hip arthroplasty does not improve early postoperative outcomes: a prospective, randomized, controlled trial. J Bone Joint Surg [Am] 2005;87-A:701-10.

22. Lohe F, Eckstein F, Sauer T, Putz R. Structure, strain and function of the transverse acetabular ligament. Acta Anat (Basel) 1996;157:315-23.

23. Konrath GA, Hamel AJ, OIsen SA, Bay B, Sharkey NA. The role of the acetabular labrum and transverse acetabular ligament in load transmission in the hip. $J$ Bone Joint Surg [Am] 1998;80-A:1781-8.

24. Nishii T, Sugano N, Miki H, et al. Influence of component positions on dislocation: computed tomographic evaluations in a consecutive series of total hip arthroplasty. J Arthroplasty 2004;19:162-6.

25. Goldstein WM, Gleason TF, Kopplin M, Branson JJ. Prevalence of dislocation after total hip arthroplasty through a posterolateral approach with partial capsulectomy and capsulorrhaphy. J Bone Joint Surg [Am] 2001;83-A(Suppl 2):2-7.

26. Weeden SH, Paprosky WG, Bowling W. The early dislocation rate in primary total hip arthroplasty following the posterior approach with posterior soft-tissue repair. J Arthroplasty 2003;18:709-13.

27. van Stralen GM, Struben PJ, van Loon CJ. The incidence of dislocation after primary total hip arthroplasty using posterior approach with posterior soft-tissue repair. Arch Orthop Trauma Surg 2003;123:219-22.

28. White RE Jr, Forness TJ, AlIman JK, Junick DW. Effect of posterior capsular repair on early dislocation in primary total hip replacement. Clin Orthop 2001;393: 163-7.

29. Suh KT, Park BG, Choi YJ. A posterior approach to primary total hip arthroplasty with soft tissue repair. Clin Orthop 2004;418:162-7.

30. Dixon MC, Scott RD, Schai PA, Stamos V. A simple capsulorrhaphy in a posterior approach for total hip arthroplasty. J Arthroplasty 2004;19:373-6.

31. Berry D, Knoch M, Schleck CD, Harmsen WS. Effect of femoral head diameter and operative approach on risk of dislocation after primary total hip arthroplasty. J Bone Joint Surg [Am] 2005;87-A:2456-63. 